\title{
In-Vitro Depth-Dependent Hyperthermia of Human Mammary Gland Adenocarcinoma
}

Andrew W. Dunn ${ }^{2}$, Yu Zhang ${ }^{2}$, David Mast ${ }^{3}$, Giovanni M. Pauletti ${ }^{4}$, Hong $\mathrm{Xu}^{5}$, Jiaming Zhang ${ }^{6}$, Rodney C. Ewing ${ }^{6}$, and Donglu Shi ${ }^{1,2, *}$

1. East Hospital, The Institute for Biomedical Engineering \& Nano Science, Tongji University School of Medicine, Shanghai 200092

2. The Materials Science and Engineering Program, Dept. of Mechanical and Materials Engineering, College of Engineering and Applied Science, University of Cincinnati, Cincinnati, $\mathrm{OH} 45221$

3. Department of Physics, University of Cincinnati, Cincinnati, Ohio, 45221, USA

4. The James L. Winkle College of Pharmacy, University of Cincinnati, Cincinnati, OH, 45267

5. Nano Biomedical Research Center, School of Biomedical Engineering, Med-X Research Institute, Shanghai Jiao Tong University, Shanghai,200030, China

6. Department of Geological \& Environmental Sciences, Stanford University, Stanford, CA 94305

Corresponding Author: Donglu Shi, Email: donglu.shi@uc.edu 
Abstract: Nanoparticle mediated photothermal ablation of cancerous tissue shows promising results and applicability as a highly efficacious treatment method. As a majority of the photothermal work has been conducted with minimal attenuation of the laser before reaching the nanoparticles within surface seeded tumors in-vivo or through buffered media in-vitro, it is important to understand the effects of greater laser attenuation on photothermal efficacy mediated by changes in the scattering and absorption of the laser. Photothermal efficacy using a near infrared (NIR) $785 \mathrm{~nm}$ laser irradiating polystyrene (PS) stabilized magnetite $\left(\mathrm{Fe}_{3} \mathrm{O}_{4}\right)$ nanoparticles $\left(\mathrm{PS}-\mathrm{Fe}_{3} \mathrm{O}_{4}\right)$ is examined on MDA-MB-231 human mammary gland adenocarcinoma in-vitro. Agarose gel columns of various heights were created to simulate soft tissue and subsequently used for NIR laser attenuation. Polystyrene was found to significantly improve magnetite nanoparticle stability in serum containing media and modified Hank's Balanced Salt Solution and was able to induce significant hyperthermic ablation at mass concentrations which also did not elicit significant innate toxicity. Furthermore it was found that the polystyrene coating significantly reduced innate toxicity over 48 hours compared to uncoated magnetite. Agar gel layers provided similar optical attenuation in the NIR region to skin and prostate.

Introduction: Nanoparticle development as recently allowed for the refinement of cancer therapeutics, leading away from disseminated therapies and towards highly localized, potent treatments. This localized therapy can mediate a myriad of treatment mechanisms including hyperthermia for reduced side effects and patient recovery time. ${ }^{1-4}$ Hyperthermia provides a method of non-invasive treatment for solid state tumors requiring only direct or local intravenous injection. ${ }^{5-7}$ Magnetite $\left(\mathrm{Fe}_{3} \mathrm{O}_{4}\right)$ nanoparticles induce local hyperthermia when subject to a near 
infrared (NIR) optical source. ${ }^{1,8,9}$ This hyperthermic effect alone may provide the required thermal energy to ablate local tissue but also may act as a triggering mechanism for release of chemotherapeutics trapped within a polymer matrix surrounding the nanoparticles, ${ }^{5,8,10}$ and provide a protective to attenuate the toxicity of uncoated magnetite ${ }^{11,12}$. Previous literature has been largely aimed at the ablation of in-vitro cultures without laser attenuation ${ }^{6,8}$ or of subcutaneous tumors with minimal attenuation from biological tissue. ${ }^{6,8}, 10,13$ However a difficulty may arise with the treatment of deep seeded solid tumors from the absorption and scattering of the NIR laser as it travels through tissue. It is therefore imperative to investigate the impact of tissue scattering and absorption on the propagation of NIR lasers and efficacy of photothermal ablation. Breast cancer remains one of the highest occurring cancers in females, comprising $28.6 \%$ of newly diagnosed cases in $2015 .{ }^{14}$ Human mammary gland adenocarcinoma was therefore chosen as the in-vitro cell line. Polystyrene magnetite nanoparticles $\left(\mathrm{PS}^{-} \mathrm{Fe}_{3} \mathrm{O}_{4}\right)$ were used in conjunction with a near infrared (NIR) $785 \mathrm{~nm}$ laser to thermally ablated MDAMB-231 in-vitro cultures through varying agarose gel depths.

Materials and Methods: High glucose Dulbecco’s Modified Eagle's Medium (DMEM), penicillin, and streptomycin were obtained from Hyclone, Fisher Scientific. Fetal bovine serum (FBS) was obtained from Atlanta Biologicals. L-glutamine and minimum essential medium (MEM) non-essential amino acids 100x were obtained from CellGro, Corning. Sodium chloride $(\mathrm{NaCl})$, potassium chloride $(\mathrm{KCl})$, calcium chloride $\left(\mathrm{CaCl}_{2}\right)$, magnesium sulfate heptahydrate $\left(\mathrm{MgSO}_{4} \cdot 7 \mathrm{H}_{2} \mathrm{O}\right)$, magnesium chloride hexahydrate $\left(\mathrm{MgCl}_{2} \cdot 6 \mathrm{H}_{2} \mathrm{O}\right)$, sodium phosphate dibasic dehydrate $\left(\mathrm{Na}_{2} \mathrm{HPO}_{4} \cdot 2 \mathrm{H}_{2} \mathrm{O}\right)$, potassium phosphate monobasic $\left(\mathrm{KH}_{2} \mathrm{PO}_{4}\right)$, glucose, sodium bicarbonate $\left(\mathrm{NaHCO}_{3}\right)$, iron chloride tetrahydrate $\left(\mathrm{FeCl}_{2} \bullet 4 \mathrm{H}_{2} \mathrm{O}\right)$, iron chloride hexahydrate $\left(\mathrm{FeCl}_{3} \cdot 6 \mathrm{H}_{2} \mathrm{O}\right)$, sodium hydroxide $(\mathrm{NaOH})$, and Agarose Type I, low electroendosmosis (EEO) 
were obtained from Sigma Aldrich. Nitrogen $\left(\mathrm{N}_{2}\right)$ gas was obtained from Praxair, Inc. $\mathrm{PS}_{-} \mathrm{Fe}_{3} \mathrm{O}_{4}$ nanoparticles were a generous gift from Jiao Tong University, Shanghai. ${ }^{15}$

Synthesis of Uncoated $\mathrm{Fe}_{3} \mathrm{O}_{4}$ Nanoparticles: Uncoated $\mathrm{Fe}_{3} \mathrm{O}_{4}\left(\mathrm{U}-\mathrm{Fe}_{3} \mathrm{O}_{4}\right)$ nanoparticles were synthesized by the co-precipitation method. $2.00 \mathrm{~g}$ of $\mathrm{FeCl}_{2} \bullet 4 \mathrm{H}_{2} \mathrm{O}$ and $5.5 \mathrm{~g}$ of $\mathrm{FeCl}_{3} \bullet 6 \mathrm{H}_{2} \mathrm{O}$ were dissolved in distilled $\mathrm{H}_{2} \mathrm{O}$ at $80{ }^{\circ} \mathrm{C}$ under $\mathrm{N}_{2}$ and left to stir for 30 minutes. $5 \mathrm{ml}$ of $1.5 \mathrm{M}$ $\mathrm{NaOH}$ was slowly pipetted into the reaction vessel and the solution was left to stir for a further 30 minutes at $90{ }^{\circ} \mathrm{C}$. Following nanoparticle formation, the $\mathrm{Fe}_{3} \mathrm{O}_{4}$ nanoparticles were purified through magnetic separation with several washes of distilled $\mathrm{H}_{2} \mathrm{O}$.

Preparation of Complete-DMEM (cDMEM): DMEM was completed through the addition of aliquots of FBS, L-glutamine, penicillin/streptomycin, and MEM non-essential amino acids in a volume ratio of 100:10:1:1.

Preparation of Modified Hank's Balanced Salt Solution (mHBSS): The following components were added to $20 \mathrm{ml}$ sterile de-ionized water: $0.4 \mathrm{~g} \mathrm{NaCl}, 0.4 \mathrm{~g} \mathrm{KCl}, 0.14 \mathrm{~g} \mathrm{CaCl}_{2}$, $0.1 \mathrm{~g} \mathrm{MgSO}_{4} \bullet 7 \mathrm{H}_{2} 0,0.1 \mathrm{~g} \mathrm{MgCl}_{2} \bullet 6 \mathrm{H}_{2} \mathrm{O}, 0.06 \mathrm{~g} \mathrm{Na}_{2} \mathrm{HPO}_{4} \bullet 2 \mathrm{H}_{2} \mathrm{O}, 0.06 \mathrm{~g} \mathrm{KH}_{2} \mathrm{PO}_{4}, 1.0$ g glucose, $0.35 \mathrm{~g} \mathrm{NaHCO}_{3}$. A $1 \mathrm{ml}$ aliquot was then added to $50 \mathrm{ml}$ of sterile de-ionized water and the $\mathrm{pH}$ was adjusted to 7.4

Preparation of Agar Layer: Agarose Type 1, low EEO was used to form 0.5, 1, 1.5, and 2.0 percent gel layers. After addition of the agarose to distilled water, the solution was heated in a microwave oven to form a homogeneous solution. The solution was then added into clear borosilicate glass vials to form varying gel depths. The optical attenuation coefficients for the varying percent agarose gels were measured using a Hitachi U-3010 Spectrophotometer. 
Nanoparticle Characterization: The z-average hydrodynamic diameter and zeta potential were quantified by a Zetasizer Nano ZS (Malvern Instruments, Ltd.) to investigate colloidal stability in cDMEM and mHBSS. Suspensions of $0.3 \mathrm{mg} / \mathrm{ml}$ uncoated $\mathrm{Fe}_{3} \mathrm{O}_{4}$ and PS$\mathrm{Fe}_{3} \mathrm{O}_{4}$ samples were created in cDMEM and mHBSS. Hydrodynamic size was recorded at 0, 24, and 48 hours following incubation at $37^{\circ} \mathrm{C}$ in serum containing media and zeta-potential at the 0 time point. Stability in mHBSS was determined through examining the hydrodynamic diameter at $0,1,2$, and 3 hours at $37{ }^{\circ} \mathrm{C}$ and zeta potential at the 0 time point. Prior to incubation at $37^{\circ} \mathrm{C}$ all samples were sonicated for 30 minutes. All measurements were recorded in triplicate.

Cell Culture: MDA-MB-231 cells were cultured in-vitro with a feeding cycle of Monday-Wednesday-Friday using cDMEM in T-75 vent cap flask (Sarstedt). Cells were split on Mondays using $0.25 \%$ trypsin-EDTA (HyClone, Fisher Scientific). Cultures were maintained at $37{ }^{\circ} \mathrm{C}, 5 \% \mathrm{CO}_{2}$, saturated humidity.

Innate Toxicity: Concentrations of 1, 5, 10, 25, 50, 100, 200, 500, 1000, 2500, and 7500 $\mu \mathrm{g} / \mathrm{ml} \mathrm{U}-\mathrm{Fe}_{3} \mathrm{O}_{4}$ and PS-Fe $\mathrm{O}_{4}$ were created through serial dilutions with cDMEM. White 96 well culture plates (Corning®) were seeded with $\sim 3,000$ cells/ well 24 hours before nanoparticle introduction. Following 24 hours after seeding, the cDMEM in each well was replaced with 100 $\mu 1$ of nanoparticle solutions. Cellular viability was quantified 48 hours following introduction of nanoparticle solutions $(\mathrm{n}=6)$. After 48 hours each well was washed with fresh cDMEM. Cellular viability was quantified through the ATP based CellTiter-Glo® luminescent cell viability assay. To each well, $100 \mu \mathrm{l}$ of reconstituted CellTiter-Glo® assay was added and the plate was placed on an orbital plate shaker for 20 minutes before quantification of luminescent output by a POLARstar Optima plate reader. Innate toxicity was calculated using the relative luminescence of the test $\left(I_{\text {test }}\right)$ and negative $\left(I_{+c o n t r o l}\right)$ control wells as follows: 


$$
\frac{I_{\text {test }}}{I_{\text {+control }}} * 100=\% \text { viability }
$$

In-Vitro Hyperthermia: MDA-MB-231 cultures were seeded into 48 well plates 24 hours prior to hyperthermia trials. During hyperthermic ablation, a baseline temperature of $37^{\circ} \mathrm{C}$ was maintained by a Fisher Scientific hot plate and temperatures were monitored by an infrared camera (FLIR T-460). A $785 \mathrm{~nm}$ NIR laser (5 watt) was collimated and passed through agar layers of various depths before irradiating individual wells. The spot size of the collimated lens was adjusted to match the diameter of an individual well in the 48 well plates. Agar gels were positioned and held in place beneath the collimation tube using a clamping system. The diameter of the borosilicate vials were such that the collimated laser was allowed to pass through the vials without attenuation from the vial walls. $\mathrm{PS}-\mathrm{Fe}_{3} \mathrm{O}_{4}$ in $\mathrm{HBSS}$ at a concentration $300 \mu \mathrm{g} / \mathrm{ml}$ was created and subsequently used in conjunction with NIR irradiation $\left(13.1 \mathrm{~kW} / \mathrm{m}^{2}\right)$ for hyperthermia trials $(\mathrm{n}=3)$. The negative control for photothermal ablation was subject to pure mHBSS with irradiation. All solutions were maintained at $37^{\circ} \mathrm{C}$ by a water bath $(n=3)$. mHBSS of test wells were replaced with $\mathrm{PS}-\mathrm{Fe}_{3} \mathrm{O}_{4}$ solutions directly prior to irradiation $(\mathrm{n}=3)$. These PS- $\mathrm{Fe}_{3} \mathrm{O}_{4}$ solutions were then replaced with pure mHBSS immediately following 15 minutes of irradiation. All wells were replaced with complete DMEM following the final irradiation and cells were incubated for 48 hours before viability quantification using the ATP based CellTiterGlo $^{\circledR}$ assay. A minimum of three repetitions were completed for each trial. 


\section{Results}

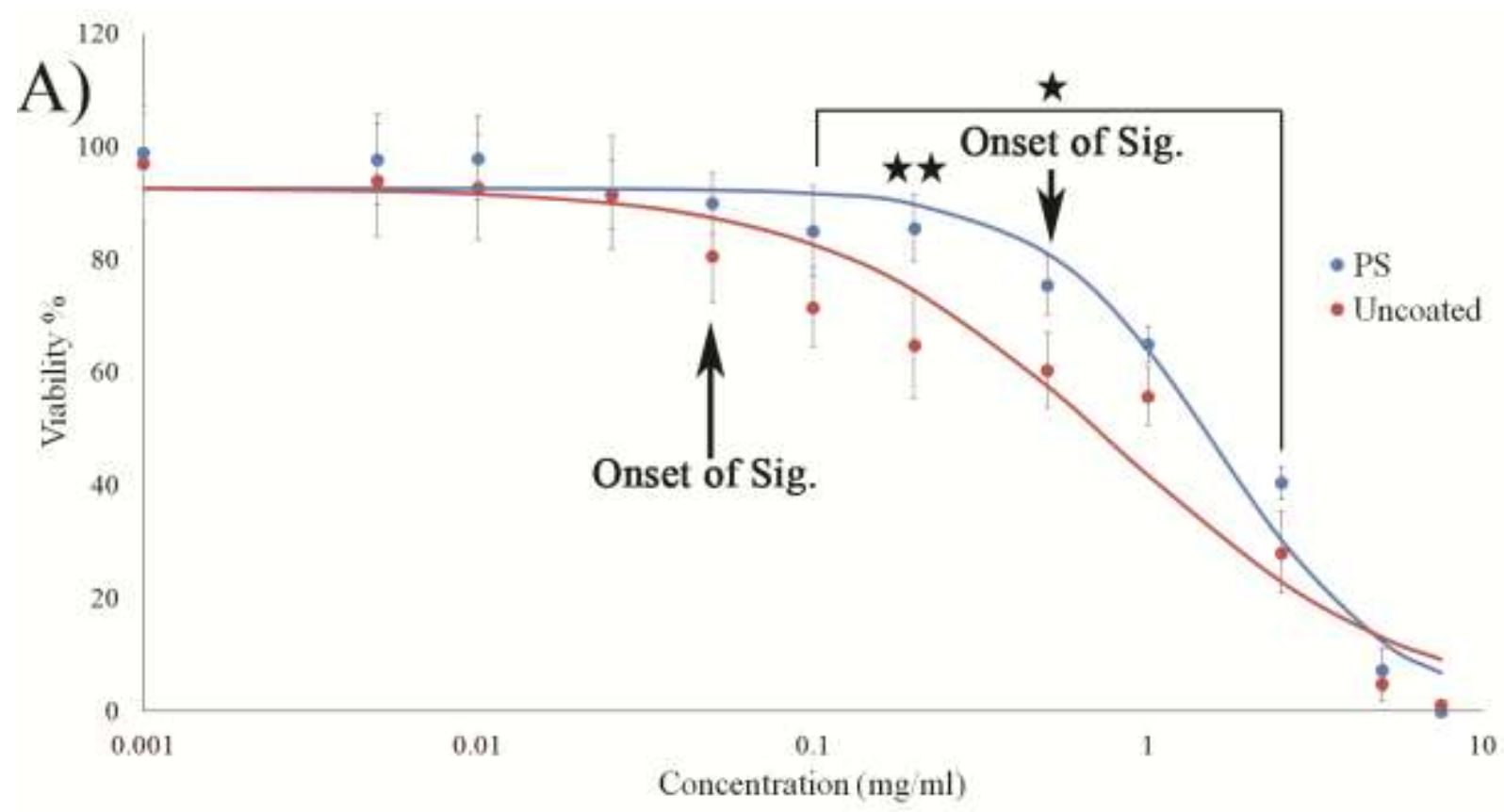

B)

Hydrodynamic Diameter ( $\mathrm{nm})$

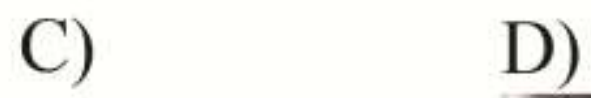

cDMEM

${\mathrm{U}-\mathrm{Fe}_{3} \mathrm{O}_{4}}^{1000+} 1000+1000+$

Figure 1: A) Innate toxicity of $\mathrm{PS}-\mathrm{Fe}_{3} \mathrm{O}_{4}$ and $\mathrm{U}-\mathrm{Fe}_{3} \mathrm{O}_{4}$. Significant values for difference in toxicity reported as $\mathrm{p}<0.001(* *)$ and $\mathrm{p}<0.05(*)$, onset of significance begins at $\mathrm{p}<0.05$. $\mathrm{B}$ ) Hydrodynamic sizes of PS- $\mathrm{Fe}_{3} \mathrm{O}_{4}$ and $\mathrm{U}-\mathrm{Fe}_{3} \mathrm{O}_{4}$ in cDMEM over 48 hours. C) Zeta Potential of PS- $\mathrm{Fe}_{3} \mathrm{O}_{4}$ and $\mathrm{U}-\mathrm{Fe}_{3} \mathrm{O}_{4}$ in cDMEM D) Transmission electron micrograph of PS- $\mathrm{Fe}_{3} \mathrm{O}_{4}$.

Fig. 1a shows the innate toxicity curve for $\mathrm{PS}-\mathrm{Fe}_{3} \mathrm{O}_{4}$ and $\mathrm{U}-\mathrm{Fe}_{3} \mathrm{O}_{4}$ for concentrations of 0.001-7.5 $\mathrm{mg} / \mathrm{ml}$. Polystyrene was observed to reduce the toxicity of magnetite in MDA-MB-231 cultures. The onset of significant reduction in viability mediated by the uncoated innate toxicity 
occurred at $50 \mu \mathrm{g} / \mathrm{ml}$, similar to previous studies ${ }^{11,16}$, while the polystyrene coating attenuated this innate toxicity. The onset of significant reduction in viability for the $\mathrm{PS}-\mathrm{Fe}_{3} \mathrm{O}_{4}$ occurred at a mass concentration of $500 \mu \mathrm{g} / \mathrm{ml}$, a 10 fold increase over uncoated magnetite. This trend is mirrored by the observance of significant differences between $\mathrm{PS}-\mathrm{Fe}_{3} \mathrm{O}_{4}$ and $\mathrm{U}-\mathrm{Fe}_{3} \mathrm{O}_{4}$ innate toxicity curves with significant differences appearing at $100 \mu \mathrm{g} / \mathrm{ml}$. Both nanoparticles possessed significant aggregation through the 48 hour time point in cDMEM with significance levels of PS$\mathrm{Fe}_{3} \mathrm{O}_{4}$ and $\mathrm{U}-\mathrm{Fe}_{3} \mathrm{O}_{4}$ at $\mathrm{p}=0.013$ and $\mathrm{p}<0.0001$ by the unpaired t-test respectively. This stability is reflected in the zeta potential for both nanoparticles in cDMEM. However in mHBSS a significantly lower colloidal size for $\mathrm{PS}-\mathrm{Fe}_{3} \mathrm{O}_{4}$ is observed for the initial time point compared to cDMEM, $\mathrm{p}=0.0002$, but immediate aggregation of $\mathrm{U}-\mathrm{Fe}_{3} \mathrm{O}_{4}$ was observed. Transmission electron micrograph of $\mathrm{PS}-\mathrm{Fe}_{3} \mathrm{O}_{4}$ shows multiple magnetite nuclei within the polystyrene matrix.

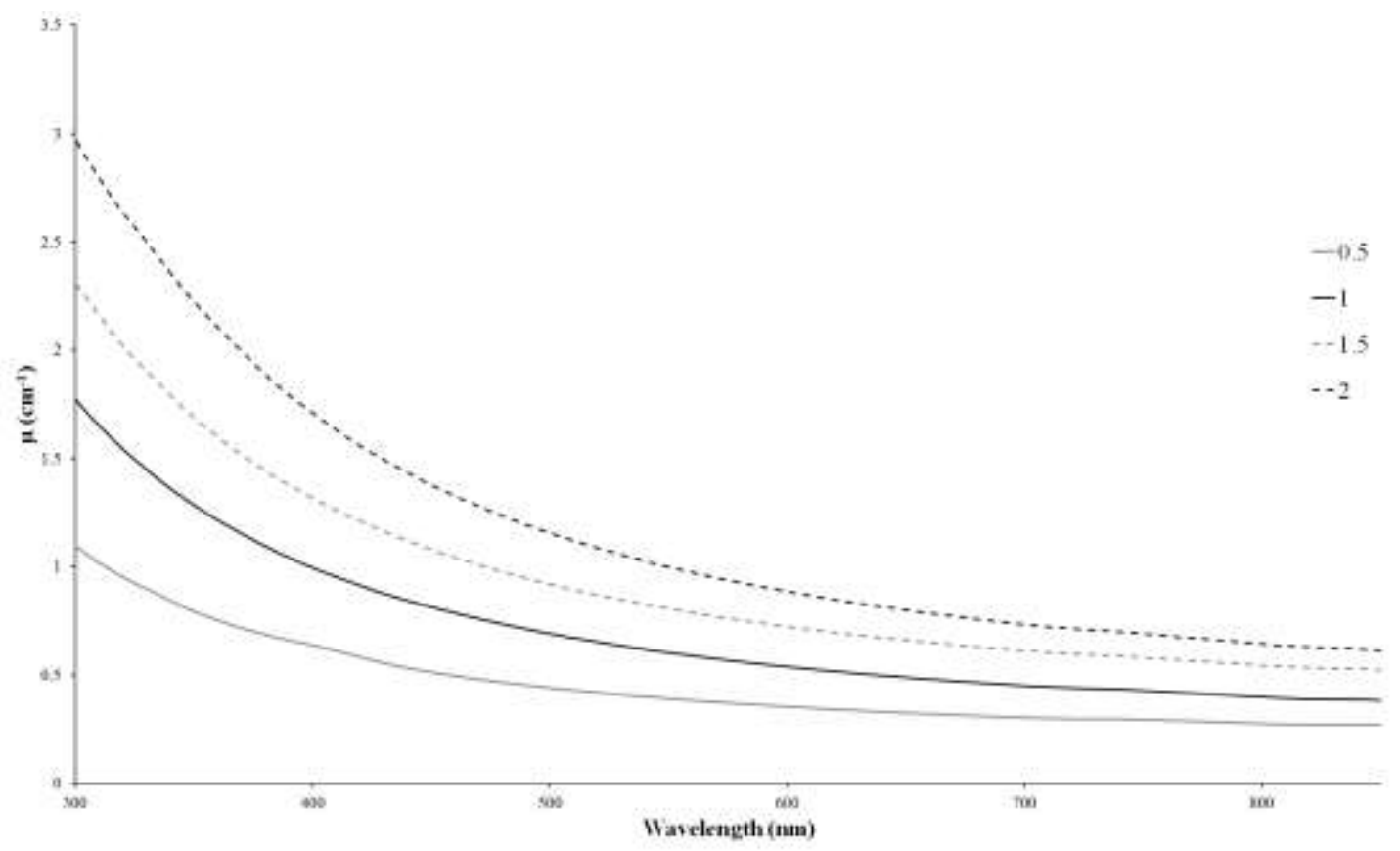

Figure 2: Optical attenuation of $0.5,1.0,1.5$, and 2.0 mass percentage agarose gels. 
The combined optical attenuation coefficient for the visible spectrum of various mass percent agarose gels were measured by a Hitachi U-3010, shown in Fig. 2. In the NIR region the agar layers display a nearly constant attenuation. Furthermore, this attenuation is close to that of the absorption of human skin $\left(\mu_{\mathrm{a}}=0.51-0.64 @ 661 \mathrm{~nm}, \mu_{\mathrm{a}}=0.16-0.23 @ 800 \mathrm{~nm}\right)$ and prostate $\left(\mu_{\mathrm{a}}\right.$ $=0.11-1.6 @ 762 \mathrm{~nm})^{17}$ with a measured combined attenuation coefficient of 0.283,0.409, 0.557 , and $0.66 \mathrm{~cm}^{-1}$ for $0.5,1.0,1.5$, and $2.0 \% \mathrm{w} / \mathrm{v}$ respectively.

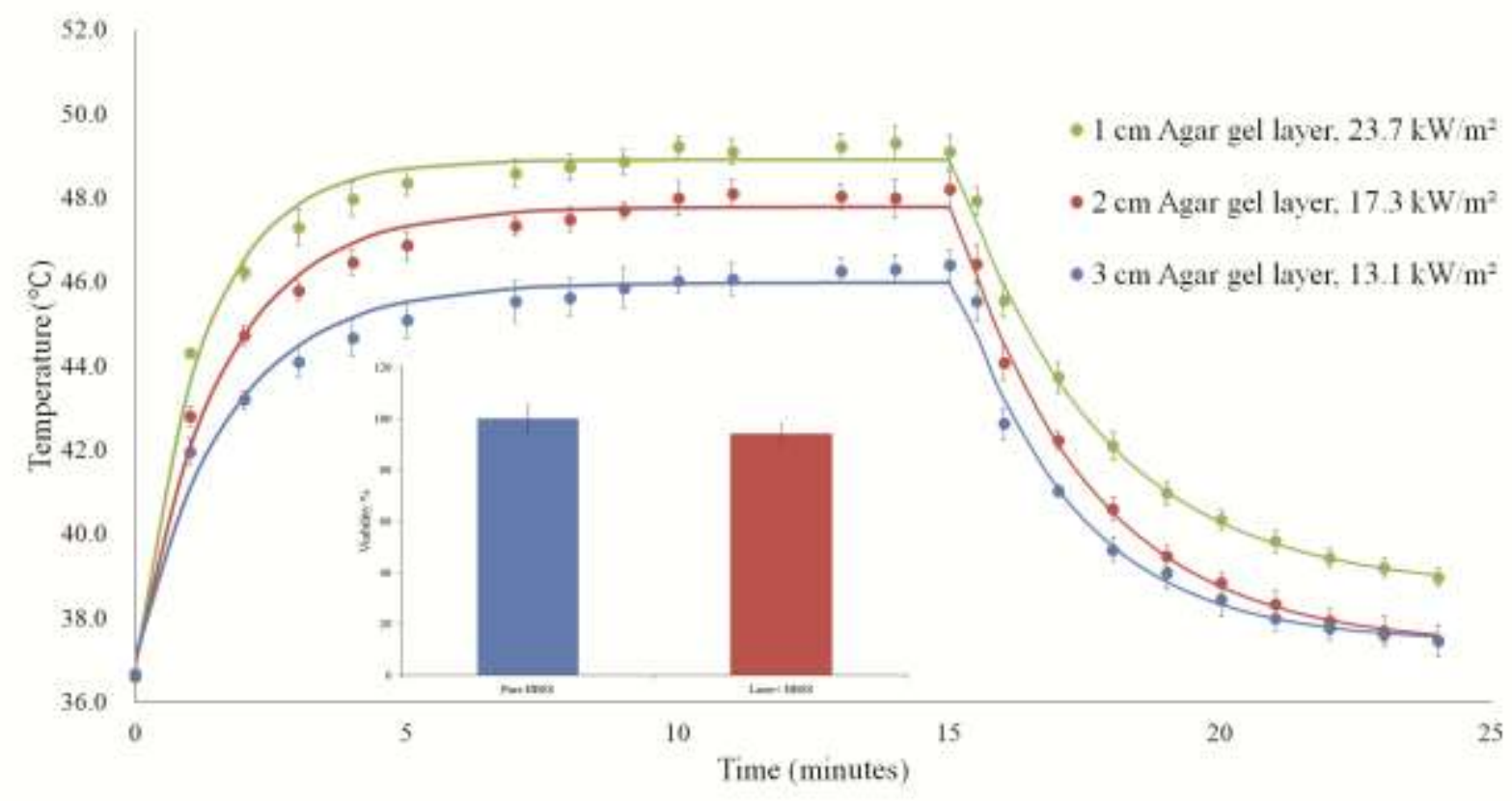

Figure 3: Hyperthermia of $300 \mu \mathrm{g} / \mathrm{ml} \mathrm{PS}-\mathrm{Fe}_{3} \mathrm{O}_{4}$ irradiated with a $785 \mathrm{~nm}$ NIR laser at various optical densities and agar gel depths. Inset) Impact of $785 \mathrm{~nm}$ NIR laser. MDA-MB-231 cultures were irradiated for 15 minutes at an optical intensity of $23.4 \mathrm{~kW} / \mathrm{m}^{2}$.

A general temperature threshold for the onset of cell death by thermal ablation is taken to be $42{ }^{\circ} \mathrm{C} .{ }^{18}$ Therefore an irradiation strategy was developed which would allow for this temperature threshold to be reached while utilizing various agar depths and a $\mathrm{PS}-\mathrm{Fe}_{3} \mathrm{O}_{4}$ concentration that would not elicit a significant innate toxicity. Fig. 3 shows the heating profile of PS- $\mathrm{Fe}_{3} \mathrm{O}_{4}$ at a mass concentration of $300 \mu \mathrm{g} / \mathrm{ml}$ irradiated with a $785 \mathrm{~nm}$ NIR laser at optical densities of $23.7,17.3$, and $13.1 \mathrm{~kW} / \mathrm{m}^{2}$ with respective agar depths of 1,2 , and $3 \mathrm{~cm}$. To 
determine the impact of the $785 \mathrm{~nm}$ laser, MDA-MB-231 cultures in HBSS were irradiated for 15 minutes at an optical intensity of $23.4 \mathrm{~kW} / \mathrm{m}^{2}$. No significant difference was found between the cultures subjected only to pure HBSS and cultures subjected to both pure HBSS and irradiation. Significant differences arising from hyperthermic ablation are considered to be from the impart of thermal energy as the mass concentration of $\mathrm{PS}-\mathrm{Fe}_{3} \mathrm{O}_{4}$ used during hyperthermia did not elicit a significant innate toxicity.

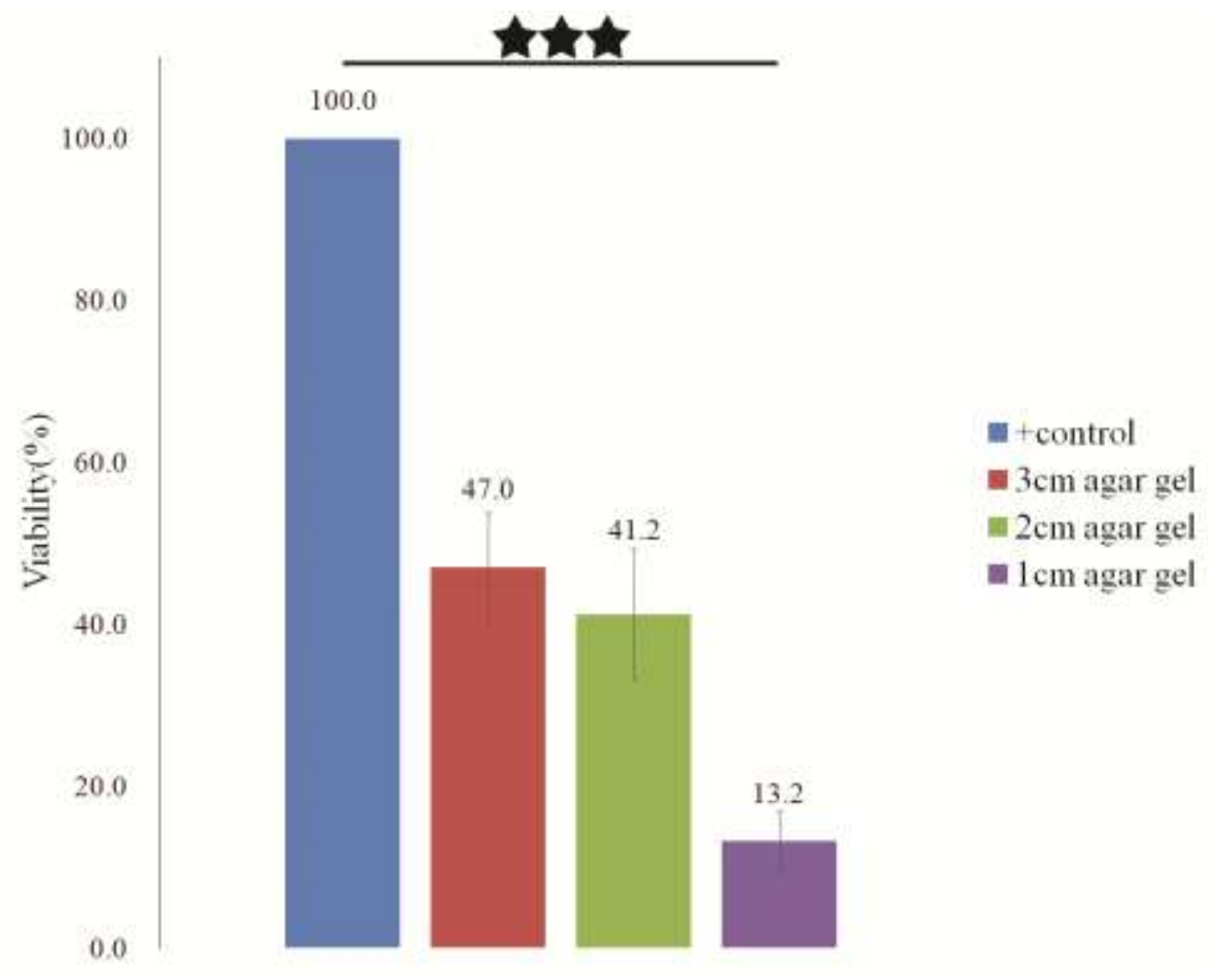

Figure 4: Hyperthermic ablation of MDA-MB-231 cultures with $\mathrm{PS}-\mathrm{Fe}_{3} \mathrm{O}_{4}$ at a mass concentration of $300 \mu \mathrm{g} / \mathrm{ml}$. Optical densities for the 1, 2, and $3 \mathrm{~cm}$ agar layers were 23.7, 17.3, and $13.1 \mathrm{~kW} / \mathrm{m}^{2}$ respectively.

Fig. 4 shows the hyperthermic ablation of MDA-MB-231 cultures with significant reductions to cell viability achieved at all gel depths relative to the negative control with 
$\mathrm{p}<0.0001$. The negative control was established by irradiating the cultures subjected to HBSS without $\mathrm{PS}-\mathrm{Fe}_{3} \mathrm{O}_{4}$ at an optical intensity of $23.4 \mathrm{~kW} / \mathrm{m}^{2}$. Optical intensities for the 1,2 , and $3 \mathrm{~cm}$ agar layers were $23.7,17.3$, and $13.1 \mathrm{~kW} / \mathrm{m}^{2}$ respectively. As the $785 \mathrm{~nm}$ NIR laser did not significantly reduce the viability of the cultures, shown in Fig. 3, the reduction in viability is due to hyperthermic ablation. The general expected trend is observed that a greater change in temperature $(\Delta \mathrm{T})$, with a maximum temperature above the $42{ }^{\circ} \mathrm{C}$ threshold, will impart a greater degree of thermal ablation.

\section{Discussion}

Hyperthermic ablation of MDA-MB-231 cultures was completed under varying optical intensities using agar gels to simulate soft tissue. The innate toxicity of $\mathrm{PS}-\mathrm{Fe}_{3} \mathrm{O}_{4}$ was initially determined to identify applicable mass concentrations of $\mathrm{PS}-\mathrm{Fe}_{3} \mathrm{O}_{4}$ for photothermal ablation. Fig. 1 shows the innate toxicity profiles for $\mathrm{U}-\mathrm{Fe}_{3} \mathrm{O}_{4}$ and $\mathrm{PS}-\mathrm{Fe}_{3} \mathrm{O}_{4}$. The polystyrene coating was able to substantially improve biocompatibility and colloidal stability in mHBSS whereas immediate aggregation of $\mathrm{U}-\mathrm{Fe}_{3} \mathrm{O}_{4}$ was observed in mHBSS. Protein coronas develop rapidly from the surface adsorption of serum proteins onto nanoparticles. ${ }^{19-21}$ This adsorption is thought to stem from the high surface energy of the nanoparticle surface ${ }^{20}$ and is characterized by an increase in size and negative shift in zeta potential. ${ }^{19}$ It is clear that this serum corona is necessary for stabilization of $\mathrm{U}-\mathrm{Fe}_{3} \mathrm{O}_{4}$ compared to dispersion in mHBSS. However as the zeta potentials for $\mathrm{PS}-\mathrm{Fe}_{3} \mathrm{O}_{4}$ and $\mathrm{U}-\mathrm{Fe}_{3} \mathrm{O}_{4}$ are not significantly different in mHBSS, the aggregation mechanism behind $\mathrm{U}-\mathrm{Fe}_{3} \mathrm{O}_{4}$ in $\mathrm{mHBSS}$ is unclear as $\mathrm{PS}-\mathrm{Fe}_{3} \mathrm{O}_{4}$ remains as a stable colloid.

With the onset of significant toxicity beginning at a mass concentration of $500 \mu \mathrm{g} / \mathrm{ml}$, concentrations below this were deemed applicable for hyperthermic ablation as the innate 
toxicity would not significantly impact the cellular viability. Agar gel layers of a low mass percent were found to attenuate NIR radiation similarly to subcutaneous fat. ${ }^{22}$ Furthermore the attenuation profile in the NIR region is fairly constant, thus providing a convenient starting gel material for further development of soft tissue models. At a $\mathrm{PS}-\mathrm{Fe}_{3} \mathrm{O}_{4}$ concentration of 300 $\mu \mathrm{g} / \mathrm{ml}$, application of a $785 \mathrm{~nm}$ laser was able to achieve a maximum temperature above the 42 ${ }^{\circ} \mathrm{C}$ threshold within 5 minutes. Furthermore the $785 \mathrm{~nm}$ laser did not induce a significant reduction in cellular viability, as shown in Fig. 3. Therefore any significant reduction in cellular viability would come from pure hyperthermic ablation induced by the laser application to the PS$\mathrm{Fe}_{3} \mathrm{O}_{4}$. With collimated $785 \mathrm{NIR}$ optical intensities of $23.7,17.3$, and $13.1 \mathrm{~kW} / \mathrm{m}^{2}$ for the 1,2 , and $3 \mathrm{~cm}$ agar gel depths respectively, a 15 minute irradiation period was able to significantly reduce cellular viability with $\mathrm{p}<0.0001$ at all depths and demonstrates the applicability for NIR wavelengths to be used for optical hyperthermia through soft tissue.

\section{Conclusion}

Magnetite nanoparticles provide a powerful tool for optical hyperthermia for the treatment of solid tumors where conventional chemotherapeutics or magnetic hyperthermia may provide deleterious side effects or be inapplicable; magnetite benefits twofold from polymeric coatings as these coatings both stabilize formed colloidal suspensions and reduce innate toxicity, effectively increasing the therapeutic window. This dual phenomenon was observed for the polystyrene stabilized magnetite nanoparticles. A drawback of optical hyperthermia however is the attenuation of photons by native tissue surrounding the region of interest. Optical attenuation of agar gel was examined at various mass percentages and was found to absorb similarly to human skin and prostate ${ }^{17}$ with a convenient, minimally varying absorption spectrum in the NIR region. This provides an easily modifiable method for further investigation of the impact of soft 
tissue attenuation on incident photons for hyperthermia as tissue scattering plays a major role in attenuation. ${ }^{17,}{ }^{22}$ Novel to this study is the use of a low mass percent agarose gel for depth dependent hyperthermic ablation of in-vitro cell cultures by NIR irradiation of polystyrene stabilized magnetite nanoparticles. This approach has shown that a collimated NIR laser has significant applicability for cancer treatment and that agarose gel layers may be used as a basis for garnering a further understanding of physical challenges of using optical hyperthermia invivo.

\section{Financial Disclosure}

This research is supported by a grant from National Science Foundation with the award number EEC-1343568.

All work is original and no portion has been previously published. All parties involved possessed no conflict of interest and participated in the enclosed research purely out of interest for the advancement of scientific knowledge. 


\section{References}

1. Kobayashi, T. 2011, "Cancer hyperthermia using magnetic nanoparticles", Biotechnology Journal, vol. 6, no. 11, pp. 1342-1347.

2. Johannsen, M., Gneveckow, U., Eckelt, L., Feussner, A., Waldöfner, N., Scholz, R., Deger, S., Wust, P., Loening, S. \& Jordan, A. 2005, "Clinical hyperthermia of prostate cancer using magnetic nanoparticles: presentation of a new interstitial technique", International journal of hyperthermia, vol. 21, no. 7, pp. 637-647.

3. Cassim, S.M., Giustini, A.J., Baker, I. \& Hoopes, P.J. 2011, "Development of Novel Magnetic Nanoparticles for Hyperthermia Cancer Therapy", Energy-Based Treatment of Tissue and Assessment Vi, vol. 7901, pp. 790115.

4. Inman, B.A., Stauffer, P.R., Craciunescu, O.A., Maccarini, P.F., Dewhirst, M.W. \& Vujaskovic, Z. 2014, "A pilot clinical trial of intravesical mitomycin-C and external deep pelvic hyperthermia for non-muscle-invasive bladder cancer", International Journal of Hyperthermia, vol. 30, no. 3, pp. 171-175.

5. Li, T., Huang, C., Ruan, P., Chuang, K., Huang, K., Shieh, D. \& Yeh, C. 2013, "In vivo anticancer efficacy of magnetite nanocrystal-based system using locoregional hyperthermia combined with 5-fluorouracil chemotherapy", Biomaterials, vol. 34, no. 32, pp. 7873-7883.

6. Tian, Q., Wang, Q., Yao, K.X., Teng, B., Zhang, J., Yang, S. \& Han, Y. 2014, "Multifunctional Polypyrrole@ Fe3O4 Nanoparticles for Dual- Modal Imaging and In Vivo Photothermal Cancer Therapy", Small, vol. 10, no. 6, pp. 1063-1068.

7. Green, H.N., Crockett, S.D., Martyshkin, D.V., Singh, K.P., Grizzle, W.E., Rosenthal, E.L. \& Mirov, S.B. 2014, "A histological evaluation and in vivo assessment of intratumoral near infrared photothermal nanotherapy-induced tumor regression", International journal of nanomedicine, vol. 9, pp. 5093.

8. Chu, M., Shao, Y., Peng, J., Dai, X., Li, H., Wu, Q. \& Shi, D. 2013, "Near-infrared laser light mediated cancer therapy by photothermal effect of $\mathrm{Fe}<\mathrm{sub}>3 \mathrm{O}<\mathrm{sub}>4$ magnetic nanoparticles", Biomaterials, vol. 34, no. 16, pp. 4078-4088.

9. Schrand, A.M., Stacy, B.M., Payne, S., Dosser, L. \& Hussain, S.M. 2011, "Fundamental Examination of Nanoparticle Heating Kinetics Upon Near Infrared (NIR) Irradiation", ACS Applied Materials \& Interfaces, vol. 3, no. 10, pp. 3971-3980.

10. Shen, S., Kong, F., Guo, X., Wu, L., Shen, H., Xie, M., Wang, X., Jin, Y. \& Ge, Y. 2013, "CMCTS stabilized Fe3O4 particles with extremely low toxicity as highly efficient nearinfrared photothermal agents for in vivo tumor ablation", Nanoscale, vol. 5, no. 17, pp. 8056-8066. 
11. Ankamwar, B., Lai, T., Huang, J., Liu, R., Hsiao, M., Chen, C. \& Hwu, Y. 2010, "Biocompatibility of $\mathrm{Fe} 3 \mathrm{O} 4$ nanoparticles evaluated by in vitro cytotoxicity assays using normal, glia and breast cancer cells", Nanotechnology, vol. 21, no. 7, pp. 075102.

12. Wang, L., Neoh, K., Kang, E., Shuter, B. \& Wang, S. 2010, "Biodegradable magneticfluorescent magnetite/poly(DL-lactic acid-co-alpha,beta-malic acid) composite nanoparticles for stem cell labeling", Biomaterials, vol. 31, no. 13, pp. 3502-3511.

13. O'Neal, D.P., Hirsch, L.R., Halas, N.J., Payne, J.D. \& West, J.L. 2004, "Photo-thermal tumor ablation in mice using near infrared-absorbing nanoparticles", Cancer letters, vol. 209, no. 2, pp. 171-176.

14. Siegel, R.L., Miller, K.D. \& Jemal, A. 2015, "Cancer statistics, 2015", CA: a cancer journal for clinicians, vol. 65, no. 1, pp. 5-29.

15. Xu, H., Cui, L., Tong, N. \& Gu, H. 2006, "Development of high magnetization Fe3O4/polystyrene/silica nanospheres via combined miniemulsion/emulsion polymerization", Journal of the American Chemical Society, vol. 128, no. 49, pp. 1558215583.

16. Hussain, S., Hess, K., Gearhart, J., Geiss, K. \& Schlager, J. 2005, "In vitro toxicity of nanoparticles in BRL 3A rat liver cells", Toxicology in vitro, vol. 19, no. 7, pp. 975-983.

17. Sandell, J.L. \& Zhu, T.C. 2011, "A review of in-vivo optical properties of human tissues and its impact on PDT", Journal of biophotonics, vol. 4, no. 11-12, pp. 773-787.

18. Sapareto, S.A. \& Dewey, W.C. 1984, "Thermal dose determination in cancer therapy", International Journal of Radiation Oncology* Biology* Physics, vol. 10, no. 6, pp. 787-800.

19. Gunawan, C., Lim, M., Marquis, C.P. \& Amal, R. 2014, "Nanoparticle-protein corona complexes govern the biological fates and functions of nanoparticles", Journal of Materials Chemistry B, vol. 2, no. 15, pp. 2060-2083.

20. Monopoli, M.P., Walczyk, D., Campbell, A., Elia, G., Lynch, I., Baldelli Bombelli, F. \& Dawson, K.A. 2011, "Physical- chemical aspects of protein corona: relevance to in vitro and in vivo biological impacts of nanoparticles", Journal of the American Chemical Society, vol. 133 , no. 8 , pp. 2525-2534.

21. Lundqvist, M., Stigler, J., Cedervall, T., Berggård, T., Flanagan, M.B., Lynch, I., Elia, G. \& Dawson, K. 2011, "The evolution of the protein corona around nanoparticles: a test study", ACS nano, vol. 5, no. 9, pp. 7503-7509.

22. Jacques, S.L. 2013, "Optical properties of biological tissues: a review", Physics in Medicine and Biology, vol. 58, no. 11, pp. R37. 


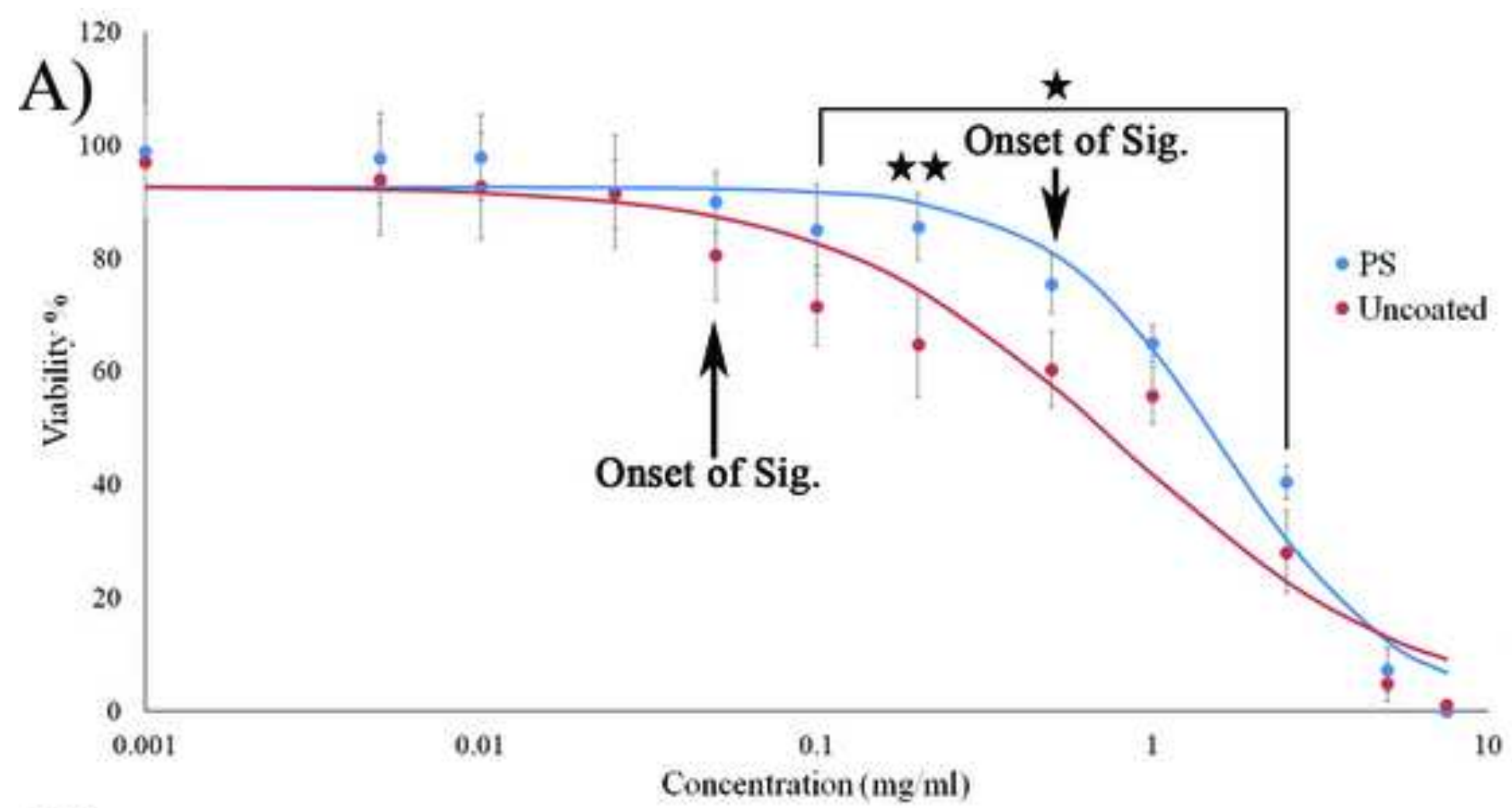

B)

Hydrodynamic Diameter ( $\mathrm{nm}$ )

\begin{tabular}{|c|c|c|c|c|c|}
\hline & \multicolumn{3}{|c|}{ cDMEM } & \multicolumn{2}{|r|}{ cDMEM } \\
\hline & $\mathrm{T}_{\mathrm{o}}$ & & $48 \mathrm{Hrs}$ & PS- $\mathrm{Fe}_{3} \mathrm{O}_{4}$ & $-9.4 \pm 0.9$ \\
\hline PS- $\mathrm{Fe}_{3} \mathrm{O}_{4}$ & $299 \pm 5$ & $394 \pm 22$ & $359 \pm 24$ & $\mathrm{U}-\mathrm{Fe}_{3} \mathrm{O}_{4}$ & $-10.1 \pm 1.1$ \\
\hline $\mathrm{U}-\mathrm{Fe}_{3} \mathrm{O}_{4}$ & $439 \pm 10$ & $487 \pm 12$ & $836 \pm 20$ & & mHBSS \\
\hline & & mHBSS & & PS-Fe ${ }_{3} \mathrm{O}_{4}$ & $-31.4 \pm-11.4$ \\
\hline & $\mathrm{T}_{\mathrm{o}}$ & $1 \mathrm{Hrs}$ & $3 \mathrm{Hrs}$ & $\mathrm{U}-\mathrm{Fe}_{3} \mathrm{O}_{4}$ & $-34.2 \pm 17.5$ \\
\hline$\frac{\mathrm{PS}-\mathrm{Fe}_{3} \mathrm{O}_{4}}{\mathrm{U}-\mathrm{Fe}_{3} \mathrm{O}_{4}}$ & $\begin{array}{c}230 \pm 8 \\
1000+\end{array}$ & $\frac{272 \pm 18}{1000+}$ & $\frac{312 \pm 27}{1000+}$ & & \\
\hline
\end{tabular}

C)

D)

\section{Zeta Potential (mV)}

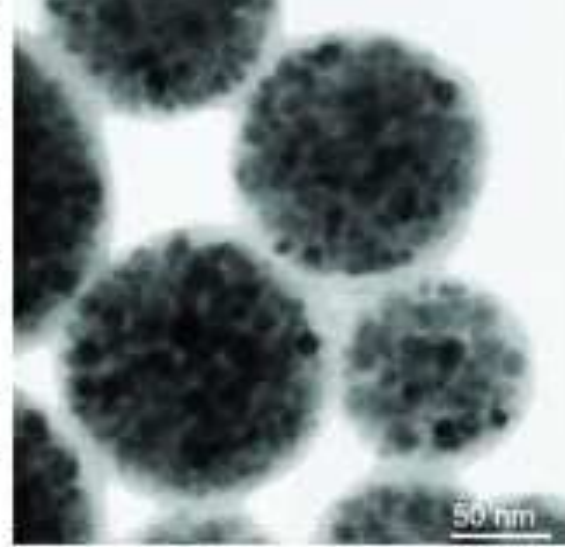




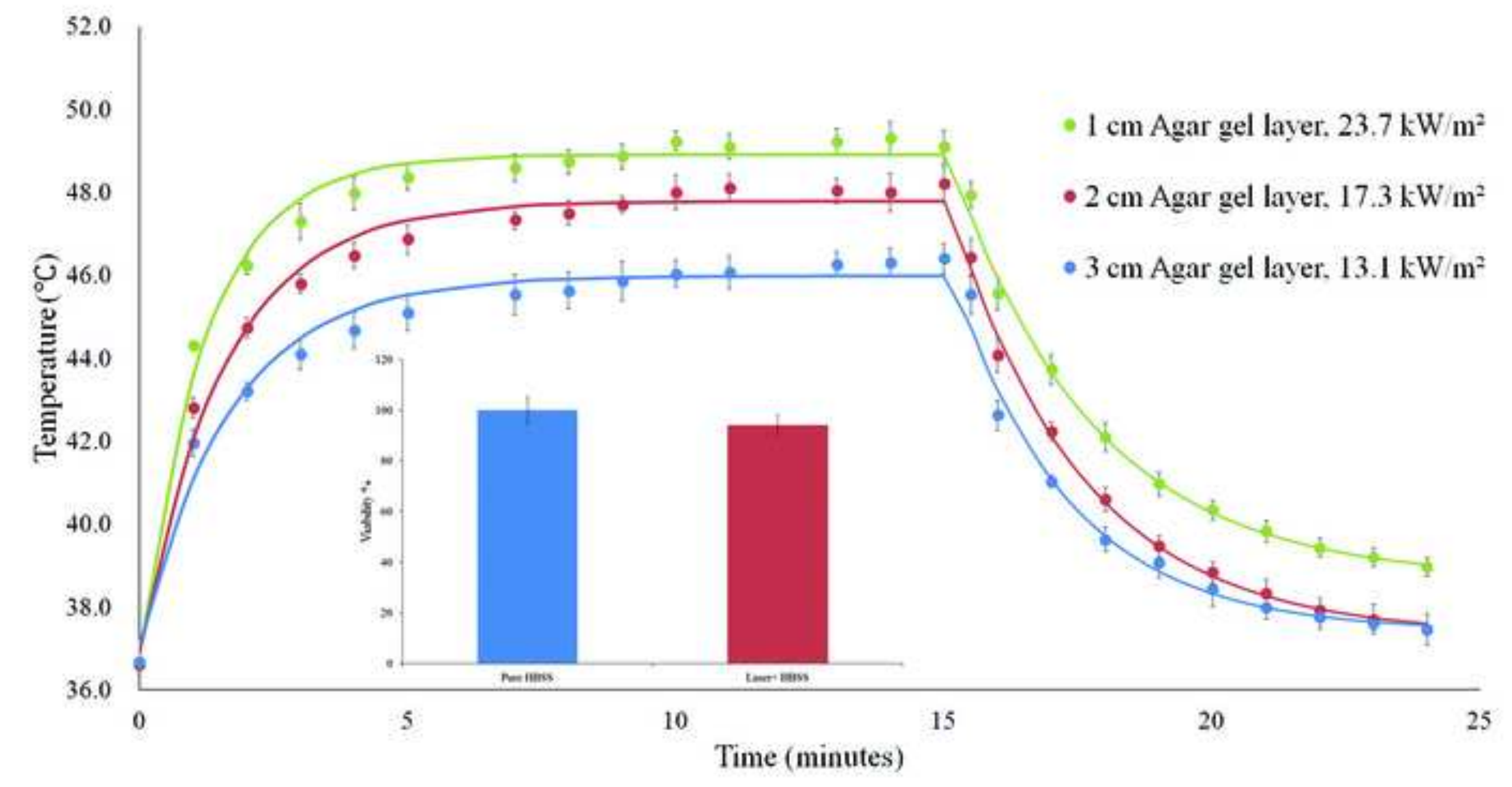




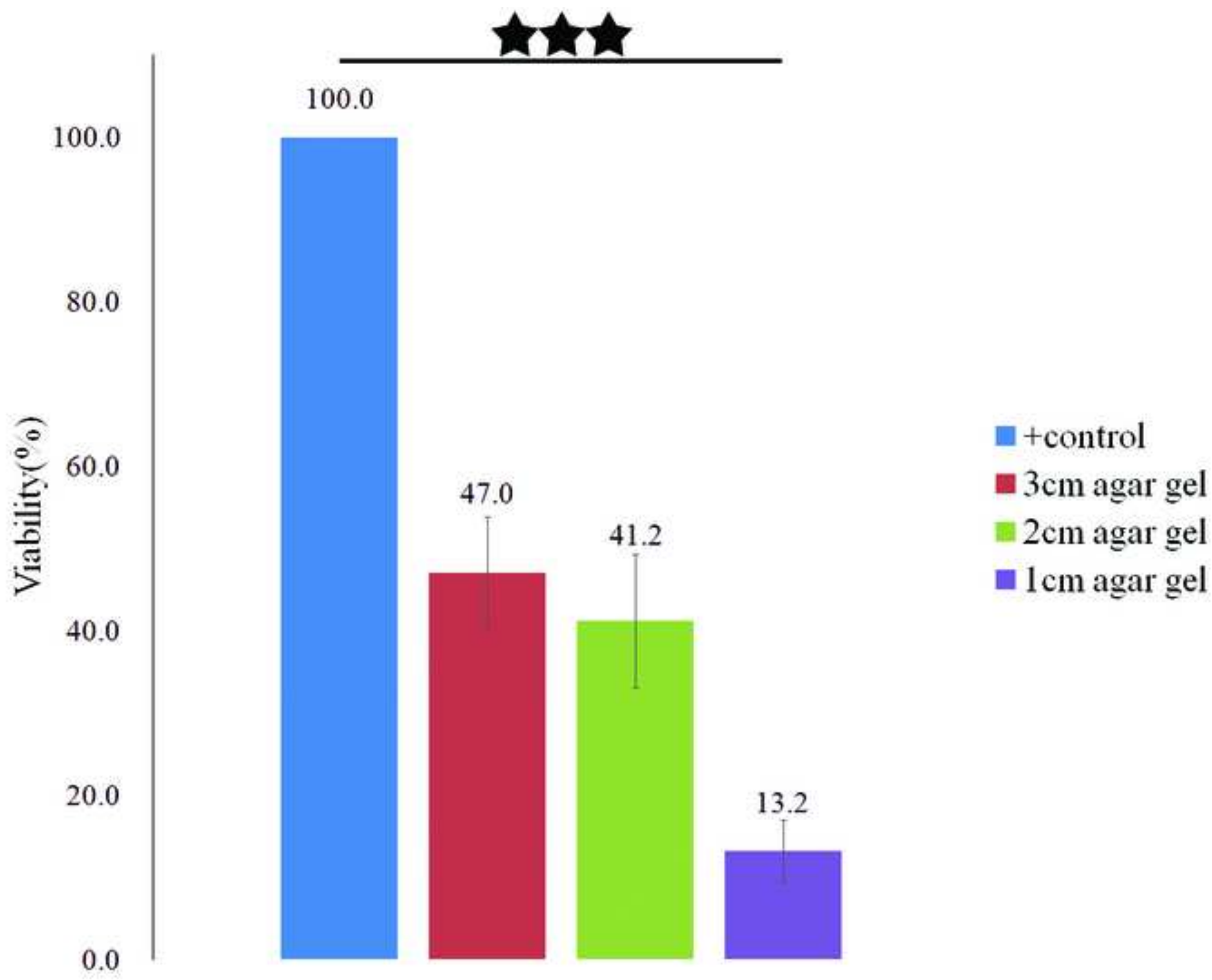

